\title{
5. The quality of life effects of enhancing public transport subsidies for hospitality workers in Vancouver, British Columbia
}

\author{
Peter V. Hall, Anthony Perl and Karen \\ Sawatzky
}

\subsection{INTRODUCTION}

What difference do public transport (PT) subsidies make to the quality of life of workers? In a research partnership between Simon Fraser University, the City of Vancouver, TransLink (the regional PT authority), the hotel workers' union, UNITE HERE Local 40, and the management of seven hotels in the urban core, hotel workers in downtown Vancouver were offered experimental PT subsidies and were surveyed about their commuting patterns, work life and housing circumstances. The research, which was completed before the COVID-19 pandemic, was designed to identify the effects of PT subsidies. The study yielded the first data that we know of regarding the mobility influences and experiences of workers in downtown Vancouver's hospitality sector. In addition, it also identified important positive effects of reported quality of life by those who received the enhanced PT subsidies. We report on those findings here, showing the invaluable role that PT plays in supporting the quality of life of service workers in the post-industrial urban economy.

The psychological and social effects of the journey to and from work have been explored by researchers over multiple scales and mobility modes (Bergstad et al., 2011; Ettema et al., 2011; Páez and Whalen, 2010). Lorenz (2018) identified commuting as a significant influence on the traveller's cognitive wellbeing, while Lachapelle et al. (2011) confirmed a relationship between travel on PT and physical activity levels that promote public health. Our analysis seeks to contextualize these findings about the relationship between the mode of travel to work and social wellbeing, in an important sector of the urban economy. 
Furthermore, while there is literature on the effects of PT subsidies on commute behaviour (see, e.g., TRB, 2005), there is relatively little written about the effects of such subsidies on specific industries and socio-demographic groups of workers. Hotel workers support tourism, business travel, conferences and conventions that connect Vancouver with the world, while also serving Vancouverites who patronize the city's hotels. Our research has revealed that the modes by which hospitality workers access their jobs in Vancouver's downtown core affects their quality of life in ways that are more nuanced than orthodox travel behaviour theory would suggest.

\subsection{DATA AND METHODS}

Practical considerations were foremost in our selection of the seven participating hotels where we would obtain data on workforce mobility. For comparison purposes, we restricted ourselves to hotels whose workers belonged to UNITE HERE Local 40. We also needed participating hotels to be willing to give us access to their premises. Finally, administering the experimental subsidy for PT commuting required that the hotels whose workforce we studied participate in TransLink's Compass for Organizations (CFO) payroll deduction programme.

Within these parameters, we sought hotels that could be assigned into pairs that had similar locations in relation to PT and pre-study availability of the PT subsidy, so that we could more easily isolate and observe the effects of the experimental subsidies. We selected two pairs that offered a monthly PT subsidy before the study: one pair located directly adjacent to a downtown SkyTrain station (Hotels A and B), and the other located a short walk from a downtown Skytrain station (Hotels C and D). We also selected a pair of hotels that did not offer a monthly PT subsidy. These two hotels were a short walk from a downtown SkyTrain station (Hotels F and G). The seventh participating hotel did not offer a monthly PT subsidy at the outset of the study (Hotel E). It was in a location that provided a good point of comparison with the second pair of hotels that offered a monthly PT subsidy prior to the start of the study.

The study was designed so that in each of the three hotel pairs, workers at one hotel would receive the new or enhanced experimental subsidies (Hotels A, D and F) while workers at the other would not (Hotels B, C and G). Workers at the final, non-paired hotel also received a new experimental subsidy (Hotel E). Pairing the hotels allowed us to compare workers' travel behaviour, including PT ridership levels and patterns, employee mode choice and commuting patterns, as well as quality of life.

Our primary data for this analysis was obtained through a survey of hotel workers, conducted in three waves over the course of a year, about their travel 
behaviour, workplace and general life satisfaction, housing arrangements and income. This survey was conducted at six-month intervals (in March 2018, September 2018 and March 2019). Every employee at the seven hotels was eligible and encouraged to participate in the surveys, regardless of their commuting mode, subsidy uptake or enrolment in TransLink's programme for employer-sponsored PT discounts. Recruitment took place at the participating hotels, with explicit support of hotel management and the union. Recruitment followed standard consent and incentive procedures, and the response rates were over 40 per cent in all three waves. These survey data provided a solid foundation for our analysis.

Using name and contact information provided when respondents gave their informed consent, we have been able to match the survey responses across the survey waves. Most importantly, we have identified and matched a subset of 444 respondents who completed both wave 1 and wave 3 surveys, which corresponds to the month of March before the experimental subsidies began, and March one year later. This group of respondents provide the basis for a quasi-panel analysis of the relationship between subsidy offer and uptake, commute behaviour and perceived quality of life.

\subsection{SOCIAL CHARACTERISTICS OF HOTEL WORKFORCE}

Transport studies, and the mobility planning practices that they feed into, tend to focus on geographical zones and mode choices, paying limited attention to the social and occupational contexts of commuting needs and behaviours (Jones and Lucas, 2012). Here, we strive to untangle and identify, where possible, how responses to the experimental subsidies varied by subgroups of our study population. We thus seek to highlight some demographic attributes of our study population to illuminate how this group of downtown hospitality workers is similar to or different from the overall population of travellers and residents in the City of Vancouver and the Vancouver census metropolitan area (CMA) (see Figure 5.1), especially when it comes to factors that may affect their commuting needs and choices. We were particularly interested in examining the effects of an increased PT subsidy on hotel workers' sense of emotional wellbeing, which has been identified as a focus for needed research (Gärling et al., 2020), and where our analysis reveals new knowledge.

\subsubsection{Age and Employment Demographics}

Our study population is somewhat older than the city and region as a whole. The percentage of the working age (20-64 years) population that is between 55 and 64 years old in the City of Vancouver is 18 per cent, and 21 per cent in 


\section{Vancouver Metropolitan Area}

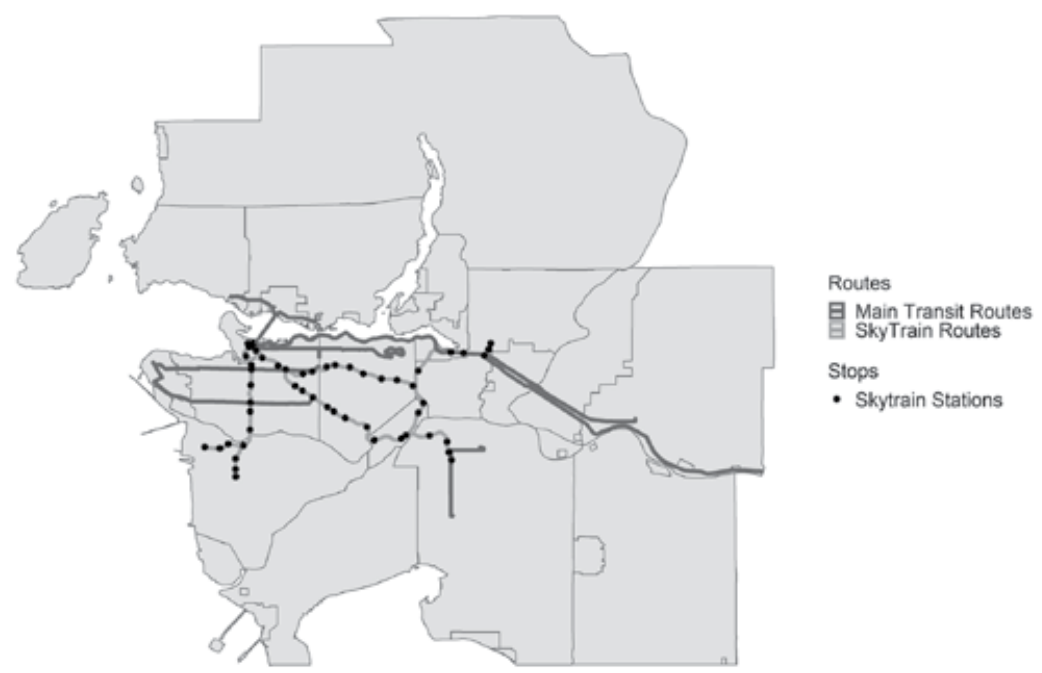

Note: Specific locations of the hotels are not indicated for confidentiality reasons.

Source: Statistics Canada, 2016 Census; TransLink, General Transit Feed Specification (7

August 2020); Data collected with Cancensus, developed by Jens von Bergmann, Dmitry

Shkolnik, Aaron Jacobs.

Figure 5.1 Vancouver census metropolitan area

the Vancouver CMA (Statistics Canada, 2016), while that age range made up 24-28 per cent of our study population. Those under 25 made up about 4 per cent of our study, whereas those in the 20-24 age group alone make up about 10 per cent of the City of Vancouver and Vancouver CMA working age populations. One implication for our study is that it may be harder to influence the commuting patterns and choices of older workers. In our study population, the average number of years a respondent had worked in their current job ranged from 11 to 13 , depending on the wave of the survey.

Hotel occupations encompass a full range of post-industrial service sector work. Housekeepers made up the largest component of our study population, at 26-29 per cent over the three survey waves, followed by food and beverage service workers (22-25 per cent), back of house workers (a diverse group including dishwashers, cooks, janitors, security and maintenance workers; 18-20 per cent), management and administration (12-15 per cent) and front of house workers (including front desk, concierges, receptionists; 10-12 per cent). 


\subsubsection{Work Schedules, Responsibilities and Commuting}

The work schedules of many hotel employees run counter to the standard daily commute patterns around which PT systems are typically organized. Across our three survey waves, 24-28 per cent of our study population reported that they did not have regular start and end times for their shifts. Workers in food and beverage service were the least likely to have regular start and end times: in the three survey waves, 37-48 per cent reported that their shift start and end times were not regular. While the majority of our study population leaves and returns home within the hours that frequent transit service (TransLink, n.d.) is available ( 6 a.m. to 9 p.m.), a substantial percentage $-36-44$ per cent in each wave - did not.

Our study population faced longer commutes than city and regional residents overall. We calculated commute times based on survey responses to questions about leaving and arrival times on the reference day. Only about 4 per cent of our respondents had commutes of 15 minutes or less, whereas in the city and region, 17 per cent and 18 per cent did. On the longer end, between 43 and 51 per cent of our study population commuted over 45 minutes during the three waves, compared to only 6 per cent of the City of Vancouver and 11 per cent of regional residents in 2016 (Statistics Canada, 2016).

Differences in the length of commute by job class were noticeable. For instance, less than 1.5 per cent of housekeepers in any of the survey waves commutes to work for 15 minutes or less. By contrast about 10 per cent of those in the management and administration job class had commutes this short. About 18 per cent of food and beverage service staff across the three survey waves had commutes of 60 minutes or more. The latter is a group of workers that tends to have irregular and off-peak hours.

We found little difference in the average duration of women's commutes compared to men's, with the exception of commutes to home with stops. The gender gap in commutes home with stops was eight minutes, with women's commutes lasting 71 minutes and men's 63 minutes. Women's longer commutes home with stops may reflect women stopping to shop or perform other household maintenance tasks on the way home. Commuting is thus a non-trivial part of hotel workers' life experience, and the vast majority of respondents do not live near their workplace. The financial and experiential terms of that commute could thus make a material difference in quality of life.

\subsubsection{Housing Characteristics}

Respondents who rent households made up 45-46 per cent of our study population over waves 1,2 and 3 of the survey. This is a considerably lower percentage of renters than in the City of Vancouver, where 53 per cent of 
households rented, according to the 2016 Census. However, regionally, renters were much below our sample, at 36 per cent of households. This means that our study population is more likely to rent than residents of Metro Vancouver overall.

We used the definition of affordability from the Canada Mortgage and Housing Corporation, which says that when a household spends more than 30 per cent of its gross income on shelter costs, that housing is unaffordable for the household (CMHC, n.d.). In each of the three survey waves, more than 30 per cent of our study population reported living in unaffordable housing (31 per cent, 34 per cent and 31 per cent for waves 1, 2 and 3, respectively). Thus, more than one-third of the survey population is under housing stress, and it should be noted that the hotels in our sample are among the city's best in terms of earning and employment stability. Any financial resource that is made available to a population in need could be expected to influence the sense of wellbeing among individuals who feel such economic pressure.

\subsection{TRAVEL CHARACTERISTICS}

We knew at the outset of this study that Vancouver's hotel workers were frequent PT users on their commutes: UNITE HERE Local 40 and hotel management both reported this, based on their front-line experience with membership and employees, respectively. The data collected for this study has offered a more detailed and nuanced picture of how these workers commute and use PT. It has also enabled us to contextualize their PT and commute patterns within city and regional mobility patterns.

Engagement with PT can be measured in different ways, including whether it is used at all, used for commuting or for non-work purposes, and whether it is combined with other modes. We focus here on use of PT, commuting modes, use of Compass Cards and monthly Compass Card products (see below), and subsidy acceptance. Most studies that look at PT use or the effect of subsidies on PT use and commuting do not specify or differentiate impacts by occupational group. These studies also do not distinguish between the general economic effect and the specific experiences that arise from making use of alternatives to the automobile.

\subsubsection{Prior Month's Public Transport Usage}

In wave 1 of the survey, 89 per cent of respondents reported taking PT in Metro Vancouver in the past month. This is considerably higher than the 52 per cent of employed Metro Vancouverites who reported doing so in the 2018 Transit Incidence Survey (Mustel Group, 2018). In the same survey, 77 per cent of the total respondents residing in the City of Vancouver and 46 per cent of those 
Table 5.1 Major commute modes and monthly pass product by hotel, wave 1

\begin{tabular}{|c|c|c|c|c|c|c|}
\hline \multirow[b]{2}{*}{ Hotel } & \multirow[b]{2}{*}{$\begin{array}{l}\text { PT subsidy } \% \text { at } \\
\text { baseline }\end{array}$} & \multicolumn{4}{|c|}{ Major commute mode } & \multirow{2}{*}{$\begin{array}{l}\text { Has a monthly } \\
\text { Compass Pass } \\
\text { product (\%) }\end{array}$} \\
\hline & & $\begin{array}{l}\text { PT-only } \\
(\%)\end{array}$ & $\begin{array}{l}\text { Walk-only } \\
(\%)\end{array}$ & $\begin{array}{l}\text { Auto-only } \\
\text { (\%) }\end{array}$ & $\begin{array}{l}\text { Auto and PT } \\
(\%)\end{array}$ & \\
\hline A & 15 & 59.8 & 12.3 & 8.7 & 16.1 & 60.1 \\
\hline B & 15 & 59.7 & 7.4 & 14.8 & 15.7 & 64.3 \\
\hline $\mathrm{C}$ & 15 & 66.0 & 6.1 & 12.3 & 9.4 & 72.1 \\
\hline D & 15 & 34.3 & 3.8 & 48.1 & 11.4 & 52.0 \\
\hline $\mathrm{E}$ & None & 63.3 & 7.8 & 21.1 & 7.8 & 66.7 \\
\hline $\mathrm{F}$ & None & 47.8 & 9.8 & 29.3 & 6.5 & 60.5 \\
\hline G & None & 50.6 & 10.1 & 30.4 & 6.3 & 56.7 \\
\hline All & & 54.0 & 7.7 & 22.5 & 12.5 & 61.6 \\
\hline
\end{tabular}

Note: The three shaded row pairs highlight comparable hotel pairs.

residing in the rest of Metro Vancouver reported using PT in the last 30 days. We also looked at PT use by job class in our study population. In wave 1, 94 per cent of housekeepers reported using PT in the last month. This was the highest percentage of any of five broad job classes, with food and beverage service workers coming in the lowest, at 83 per cent.

\subsubsection{Mode Choice}

As we see in Table 5.1 (last row), overall, 54 per cent of our respondents were PT-only commuters on the days we first surveyed them in March 2018. The percentage of people using PT to get to and from work in our study population was also substantially higher than the share of trips to work by PT reported in trip diaries completed for TransLink's 2014 Transportation Panel Survey, which was based on a representative sample of 3,071 Vancouver residents at least 15 years old (TransLink, 2014). In that data, 27 per cent of trips to work were by PT, 41 per cent by auto, 9 per cent by bike and 23 per cent by walking. In our first survey, only 23 per cent had auto-only commutes on the days we surveyed them, though another 14 per cent combined auto with PT or some other mode. Our study population was also much less likely to commute by walking or cycling than city residents, though the rates were more similar to those for the region. Thus, the subset of our population who already commute by PT could be expected to have an immediate gain in satisfaction from a reduction in the price of their travel through the subsidy program.

The proportion of hotel employees with PT-only commutes in wave 1 varied considerably by job class. Housekeepers had the highest share of this mode 
at 75 per cent, with only 38 per cent of managers and administrators making PT-only commutes. Managers and administrators had the highest percentage of auto-only commute mode, but also a high percentage of active commuters (16 per cent). Housekeepers and back of house employees had the lowest percentages of active commuters in wave 1, which makes sense given that only 3-4 per cent of housekeepers and 7-9 per cent of back of house workers lived in downtown Vancouver (across the three survey waves), compared to 18-24 per cent of those in management and administration jobs. This reflects relative housing prices.

Considerable differences in commute mode by hotel were also apparent (see Table 5.1). This is no surprise, given the locations of the pairs of hotels in relation to PT and parking. Hotel D is the least proximate to PT and has a correspondingly low PT-only commute percentage and the highest percentage of auto-only commuters, despite the availability of a 15 per cent PT subsidy. Hotel E is closer to PT than Hotel D and, despite the absence of a subsidy at the time of the wave 1 survey, had a much higher percentage of PT-only commuters.

\subsubsection{Has a Compass Card and Monthly Pass Product}

In wave 1 of the survey, 90 per cent of our total respondents had a Compass Card, which can be used to pay for single trips on an as-needed basis using 'stored value', or used as a monthly pass. Sixty-two per cent of our total respondents had some type of monthly pass product on their Compass Card at the time of the baseline survey. Although a strict comparison is not available, the rate at which these hotel workers held monthly pass products appears to be much higher than the rate among Compass Card holders in general. According to TransLink, in March 2019, 75 per cent of all Compass Cards, excluding specialty passes such as those available to university students, youth, seniors or those on income assistance, had only stored value.

Again, housekeepers held Compass Cards at the highest rate, 96 per cent. They were also the group that held monthly pass products (of some sort) at the highest rate, which was 77 per cent. The management and administration (47 per cent) and food and beverage job classes (49 per cent) had the lowest percentages of monthly pass product holders. As shown in Table 5.1, respondents at Hotel D, the least PT accessible location, held monthly pass products at the lowest rate ( 52 per cent), but the highest rates were not at those hotels adjacent to SkyTrain stations (hotels A and B), but instead were at hotels C and E, both of which are a short walk from a SkyTrain station. 


\subsubsection{Subsidy Acceptance}

In wave 1, 28 per cent of respondents said that they had accepted a PT subsidy from their employer; with 43 per cent reporting that while their employer offers a PT subsidy, they had not accepted it. Among occupational groups, housekeepers were the job class with the highest percentage of subsidy accepters in wave 1, with 41 per cent of them doing so. Front of house staff were the second biggest group to accept the subsidy at 27 per cent, followed by food and beverage service workers ( 25 per cent), management and administration (20 per cent) and back of house workers ( 20 per cent).

Subsidy acceptance also varied among the four hotels (A, B, C and D) where the 15 per cent subsidy was available at the time of the first survey, and before the new and enhanced experimental subsidies became available. Hotel $\mathrm{C}$ had the highest rate of subsidy acceptance (48 per cent) and Hotel A the lowest (21 per cent), despite its PT-proximate location. Hotel D, which is the furthest from PT, had the second lowest subsidy acceptance rate (23 per cent) and a high percentage of respondents indicating that a subsidy was available but they had not accepted it.

The data we matched from waves 1 and 3 allow us to examine the characteristics of workers who were most likely to accept the subsidy or change commuting behaviours in response to the PT subsidies. One of the characteristics of subsidy accepters was a higher likelihood to work weekends. This may reflect the current pricing advantage of weekends, which is when SeaBus and SkyTrain trips across the entire Metro Vancouver region (three zones) are priced at the one-zone fare. It is possible that the weekend discount combined with the discount from the experimental subsidy were sufficient to trigger subsidy acceptance. This would echo a broader reality in transport pricing, whereby mobility that is perceived as a good bargain draws attention and can influence travel behaviour change. This is the principle on which airlines' 'seat sales' and auto dealers' 'employee pricing for all' is based.

\subsection{QUALITY OF LIFE EFFECTS OF PUBLIC TRANSPORT}

Using eight quality-of-life indicators with a five-point Likert-type scale in all three questionnaires, we found that overall, for our entire study population, respondents reported small declines in perceived quality of life in most categories from waves 1 to 3 of the surveys. This tells us that any subsidy- or PT-related improvements in how workers perceived their quality of life were not large enough to override the overall (small) declines in perceived quality of life. After all, a new PT subsidy, or an increase to an existing PT subsidy, is only one of many factors affecting workers' perceptions of their quality of life. 
The facts that Vancouver was in the grip of a worsening housing affordability crisis, and that hotels and their employees were deadlocked in contract negotiations, may have contributed to this overall context that drove down quality of life perceptions during our survey period.

Table 5.2 shows perceived quality of life (QoL) for waves 1 and 3, with index of quality of life change in the last column. This index was calculated as wave 3 net change minus the wave 1 net change, where wave 3 net change is equal to twice 'very positive' plus 'positive' minus twice 'very negative' minus 'negative'. We do note in Table 5.2, however, that there were absolute improvements to indicators in two areas that may be closely related to commuting: stress level ( +3.1 per cent) and predictability of commute to work and to home $(+8.2$ per cent and +3.5 per cent, respectively). One of the reasons why people find commuting unpleasant and stressful is the degree to which the length of time it will take and what will happen on the way is uncertain. For example, unpredictability is a challenge for auto-only commuters in areas with traffic congestion, just as it is for PT commuters in areas with unreliable service.

In contrast, respondents reported an overall absolute decline in all other dimensions of quality of life, including general happiness with life, time spent with family and friends, physical health, shift scheduling and general happiness with work. Our analysis shows that the relative decline in some of these was smaller for those who accepted the subsidy and/or used PT.

\subsubsection{Quasi-Panel Analysis}

Among the quasi-panel of respondents matched from waves 1 to 3, 25 per cent reported a decline in happiness at work, but among those who switched away from commutes that included PT, this rate was much higher: 50 per cent. Meanwhile, only 19 per cent of those who added PT to their commutes reported a decline in their happiness at work. These differential rates of decline in reported happiness at work indicate that those whose commutes included PT were more likely to have stable or improved feelings of happiness at work than those who commuted by other modes.

Everyone in the quasi-panel of matched respondents (waves 1 to 3 ) who added PT to their commutes reported either constant or improved stress levels. Meanwhile, only 69 per cent of those in the quasi-panel who shifted away from PT in their commutes reported improved (that is, reduced) stress levels. Almost one-third (31 per cent) of those who shifted away from PT in their commutes reported increased stress levels. Whether the increased stress came from the general economic effect of losing access to a resource (PT subsidy) and having to pay more for mobility, or whether it came from the physical and psycholog- 


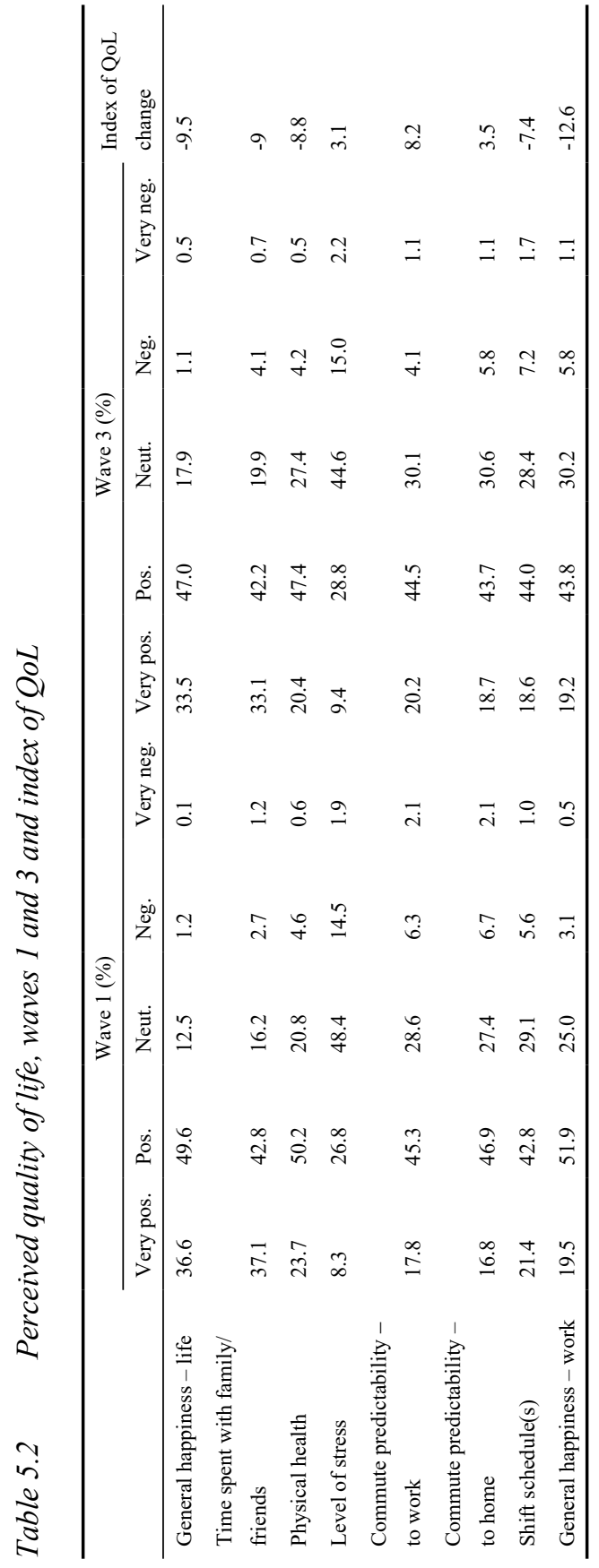


ical attributes associated with a less predictable and relaxing mode of travel, or whether both factors were operative, deserves further investigation.

Further supporting the association between reported level of stress and the use of PT in commuting, those who switched to PT-only commuting were more likely to express improved or constant stress levels: over 90 per cent, compared to only 68 per cent of those who stopped being PT-only commuters. When it comes to those who gave up auto-only commuting from waves 1 to 3, 54 per cent reported improved stress levels. This contrasts with the 100 per cent of those who switched to auto-only commuting who reported static or worsened stress levels. Note, however, that this apparently overwhelming finding may not be statistically significant due to low cell counts.

\subsubsection{Multivariate Analysis}

The positive relationship between some self-reported quality of life dimensions and PT usage, identified through bivariate analysis in the section above, was further confirmed through a series of binary logistic regressions. Here we model the likelihood of positive or very positive reports on each of the quality of life indicators, as a function of a series of independent variables including demographic characteristics, geographic (accessibility, sub region), work circumstances, and PT subsidy offer. We report on just some of the statistically significant relationships.

First, in a pooled cross-sectional sample of all respondents from all three waves, those who had accepted the subsidy were significantly more likely to report:

- Positive or very positive health $(\mathrm{p}=0.037, \operatorname{Exp}(B)=1.316)$.

- Positive or very positive level of stress $(p=0.011, \operatorname{Exp}(B)=1.366)$.

- Positive or very positive predictability of commute back home from work $(\mathrm{p}=0.026, \operatorname{Exp}(B)=1.326)$.

Subsidy acceptance was thus related to some positive quality of life outcomes, namely health, stress and commute predictability. In other words, subsidy acceptance appears to give workers a general sense of assuredness about their lives, including commute predictability, which may affect workplace outcomes. This effect appears to be an early impact of increasing available resources to a population who need all they can gather to make ends meet.

Second, among the quasi-panel of respondents matched from waves 1 to 3 , a higher initial subsidy level is associated with a greater likelihood of an improved or unchanged general happiness with life $(\mathrm{p}=0.021, \operatorname{Exp}(\mathrm{B})=$ 1.062). Third, also among the quasi-panel respondents, a higher initial subsidy level is associated with a greater likelihood of improved or unchanged pre- 
dictability of commute from home to work $(\mathrm{p}=0.004 ; \operatorname{Exp}(\mathrm{B})=1.078)$, and of the commute back home from work $(p=0.009 ; \operatorname{Exp}(B)=1.069)$. Fourth, also among the quasi-panel respondents, those accepting a subsidy between waves 1 and 3 are much more likely to report a positive change in the level of stress $(\mathrm{p}=0.000, \operatorname{Exp}(\mathrm{B})=4.454)$. This finding lends considerable support to the findings above about the positive relationship between self-reported stress level and PT engagement.

In summary, it is important to note that a higher subsidy level in the first survey was associated with improved or unchanged quality of life indicators between waves 1 and 3, including general happiness with life, level of stress, time with family and friends, and commute predictability. This supports other findings that it takes time for the implications of PT subsidies to become apparent to commuters, since commuting is a learned, routine-based behaviour. In other words, the value of shifting to a more predictable and less stressful mobility mode only becomes apparent to the users over time. Like increasing physical exercise, switching to PT may bring some initial pain and then a lag period before the benefits are felt. Subsidy acceptance was also associated with an improvement in the reported level of stress.

\subsection{CONCLUSIONS}

Our findings thus confirm that PT plays a necessary and important role in the lives of Vancouver's downtown hotel workers. Even though a substantial minority of workers commute at hours falling outside the period when PT services are planned and operated to support work trips, many hotel employees make use of PT and experience its effects on their quality of life. The unique dataset we have compiled provides a rich opportunity for analysis of the relationship between work and commuting among rarely recognized workers in post-industrial urban economies.

We have discovered from the application of an experimental PT subsidy, and occupationally and socially disaggregated survey data, that PT makes a positive contribution to the work and life satisfaction within the population that we studied. This occurred by reducing the cost of travel and improving travel reliability as compared to commuting by automobile. As a result, many hotel workers who contribute to making Vancouver a happier and more connected city can gain enhanced social wellbeing from programmes that encourage PT use. The leading and lagging components of this effect have begun to reveal themselves in our findings, but further investigation would be needed to validate these dynamics with greater confidence and precision. 


\section{ACKNOWLEDGEMENTS}

The authors gratefully acknowledge the contribution of Mr Steve Tornes, who helped with preparing the map of Vancouver appearing in this chapter. We also acknowledge and thank the team of research assistants who administered the survey of the Vancouver hotel workers. This study was made possible by the generous support of the City of Vancouver, TransLink, UNITE HERE Local 40, and the seven participating downtown hotels, including members of the Greater Vancouver Hotel Employers Association (the Westin Bayshore, Pinnacle Harbourfront, and Hyatt Regency), Holiday Inn Downtown, and Blue Horizon. The full study report is available at http://summit.sfu.ca/item/ 20608. Anonymized survey data is archived on the Federated Research Data Repository and available at https://doi.org/10.25314/dc305c6b-72c4-40b2 -aff5-51c8b6c22c55.

\section{REFERENCES}

Bergstad, C.J., Gamble, A., Gärling, T., Hagman, O., Polk, M., et al. (2011). Subjective well-being related to satisfaction with daily travel. Transportation, 38(1), 1-15.

CMHC (n.d.). Housing in Canada: definitions of variables. https://cmhc.beyond2020 .com/HiCODefinitions_EN.html\#_Affordable_dwellings_1.

Ettema, D., Gärling, T., Eriksson, L., Friman, M., Olsson, L.E., and Fujii, S. (2011). Satisfaction with travel and subjective well-being: development and test of a measurement tool. Transportation Research Part F: Traffic Psychology and Behaviour, 14(3), 167-175.

Gärling, T., Ettema, D., Connolly, F.F., Friman, M., and Olsson, L.E. (2020). Review and assessment of self-reports of travel-related emotional wellbeing. Journal of Transport and Health, 17.

Jones, P., and Lucas, K. (2012). The social consequences of transport decision-making: clarifying concepts, synthesising knowledge and assessing implications. Journal of Transport Geography, 21, 4-16.

Lachapelle, U., Frank, L., Saelens, B.E., Sallis, J.F., and Conway, T.L. (2011). Commuting by public transit and physical activity: where you live, where you work, and how you get there. Journal of Physical Activity and Health, 8(1), S72-S82.

Lorenz, O. (2018). Does commuting matter to subjective well-being? Journal of Transport Geography, 66, 180-199.

Mustel Group (2018). TransLink Transit Incidence Survey. June 2018. Dataset 1.

Páez, A., and Whalen, K. (2010). Enjoyment of commute: a comparison of different transportation modes. Transportation Research Part A: Policy and Practice, 44(7), 537-549.

Statistics Canada (2016). Census Profile, 2016 Census Vancouver, City [Census Subdivision], British Columbia and Vancouver CMA [Census metropolitan area], British Columbia [Government of Canada, n.d.], https://www12.statcan.gc.ca/census -recensement/2016/dp-pd/prof/details/page.cfm?Lang=E\&Geo1=CSD\&Code1= $5915022 \&$ Geo $2=$ CMACA\&Code $2=933 \&$ SearchText $=$ Vancouver $\&$ SearchType $=$ Begins $\&$ SearchPR $=01 \& B 1=$ All\&TABID $=1 \&$ type $=0$. 
TransLink (n.d.). Frequent Transit Network. https://www.translink.ca/Plans-and -Projects/Frequent-Transit-Network.aspx.

TransLink (2014). Transportation Panel Survey: 2014 Final Report (2014). Exhibit 4-9 - Comparison of Panel Survey Trips to Work.

TRB (Transportation Research Board and National Academies of Sciences, Engineering, and Medicine) (2005). Analyzing the Effectiveness of Commuter Benefits Programs. Washington, DC: National Academies of Science. 